\title{
Cognitive Group Therapy, Stress Management, and Desensitization Through Eye Movement Reprocessing in Reducing Depression Severity Among Patients with Spinal Cord Injuries
}

\author{
Akbar Hemmati Sabet ${ }^{1}$; Alaleh Ashouri ${ }^{2}$; Mohammad Hemmati ${ }^{2}$; Daryush Amini ${ }^{3}$; \\ Mohammad Ahmadpanah ${ }^{4,}$ \\ ${ }^{1}$ Young Researchers Club, Research and Sceince Branch, Islamic Azad Univesity, Tehran, IR Iran \\ ${ }^{2}$ Department of Psychology, Tonekabon Branch, Islamic Azad University, Tonekabon, IR Iran \\ ${ }^{3}$ Department of Psychology, Farhangian University, Hamadan, IR Iran \\ ${ }^{4}$ Research Center for Behavioral Disorders and Substances Abuse, Hamadan University of Medical Sciences, Hamadan, IR Iran \\ *Corresponding author: Mohammad Ahmadpanah, Research Center for Behavioral Disorders and Substances Abuse, Hamadan University of Medical Sciences, Hamadan, IR Iran. Tel: \\ +98-9183130671, Fax:+ 98-8138271066, E-mail: ahmadpanah@umsha.ac.ir
}

Received: March 14, 2014; Accepted: April 13, 2014

Background: During the recent decades, there have been two major leaps in treatment of depression using the medication to pacify and relieve depression signs and behavior cognitive therapy. The available evidences emphasize the treatment success with some group training methods including stress management, cognitive group therapy, and eye movement desensitization in reducing depression. Objectives: The present study aimed to compare the effectiveness of these methods on reducing depression in patients with spinal cord injuries.

Patients and Methods: In a quasi-experimental project, 60 patients with spinal cord injuries were recruited and randomly allocated to one of the following treatment groups: stress management, cognitive group therapy, and eye movement desensitization and reprocessing, and no cognitive treatment groups. Depression status and severity was determined using Beck depression inventory.

Results: Although baseline depression state was comparable across the study groups, following training, the mean depression score in the groups received eye movement desensitization $(14.60 \pm 3.15)$ and stress management $(22.66 \pm 3.37)$ were significantly lower than in cognitive group therapy $(27.33 \pm 4.15)$ or in no cognitive treatment groups $(32.13 \pm 1.80)(\mathrm{P}<0.001)$. Between-group covariate analysis showed superiority of eye movement desensitization method on other treatment methods including stress management and cognitive group therapy $(\mathrm{P}<0.001)$.

Conclusions: Our study showed higher effectiveness of eye movement desensitization and reprocessing methods compared with stress management and cognitive group therapy in reducing depression severity in patients with spinal cord injuries.

Keywords:Depression; Cognitive Therapy; Spinal Injuries; Eye Movement Desensitization and Processing

\section{Background}

Major depression is one of the main causes of inability and the fourth major cause of disease burden worldwide. Clinical depression is a disorder with the high lifelong incidence of $12.5 \%$ in men and $21 \%$ in women (1-3). Depression imposes economic, cultural, health, and social costs on patients, their families, and the society. Depression is becoming widespread and chronically endangering the psychological life (4). During the past 40 years, there have been two major leaps in treatment of depression: using the medication to pacify and relieve the depression signs and the behavioral-cognitive therapy. The most common medications for major depression are antidepressants, which are relatively cheap; however, depression tends to recur as half to three-fourths of the patients experience another episode of depression after two years of recovery. The main strategy to prevent recurrence of depression is to continue the drug therapy for a long time (5). In this regard, nonpharmacological approaches play a key role in treatment of these patients. Cognitive therapy focuses on cognitive changes, which are supposed to play role in the formation of depression disorder, and aims to remove depression episodes and prevent their recurrence through identifying negative recognition dynamics, establishing different positive and flexible thinking method, and practicing cognitive and behavioral responses. Based on the cognitive theory of Beck,for the commence and formation of depression, cog-

Implication for health policy/practice/research/medical education:

As there had been no study focusing on effectiveness of the cognitive therapy, stress management, and desensitization through eye movement reprocessing on depression, this study aimed to compare the effect of these three methods of cognitive therapy on depression severity in patients with spinal cord injuries.

Copyright (C) 2014, Hamadan University of Medical Sciences, Hamadan University of Medical Sciences; Published by Hamadan University of Medical Sciences. This is an open-access article distributed under the terms of the Creative Commons Attribution License, which permits unrestricted use, distribution, and reproduction in any medium, provided the original work is properly cited. 
nitive vulnerability or illogical beliefs are more important than streesors.

that include schemata and depressive beliefs $(6,7)$. Different researches have shown reducing depression-generating symptoms, ineffective attitudes, and negative automatic beliefs during the cognitive therapy (8-11). It is proposed that cognitive therapy is more effective than lack of treatment and nonspecific treatment and at least has the effect similar to medications in major depression. The follow-up studies confirmed that cognitive therapy reduces the risk of infliction after the treatment. These studies showed that respondents to medication were likely to have recurrence episodes twice as much as those received cognitive therapy $(12,13)$. As with drug effectiveness in depression, the results of researches by Mynors et al. (14) and Schulberg et al. (15) showed the suppression rate of $48 \%$ to $52 \%$ and $48 \%$ to $66 \%$ after three to eight months of antidepressants therapy and cognitive or interpersonal psychotherapy, respectively.

Introduced by Lung (1977) and Bower (1981), the method of desensitization treatment through eye movement reprocessing has been recently proposed as an influential method in reducing depression. Based on information processing, (16) this treatment includes elements of exposure therapy and behavioral therapy combined with eye movements, hand strikes, and audio stimulation, which accelerates accessibility and reprocessing traumatic memories in a compatible style and helps to release the brain from previous trauma through natural processing of emotional information. Various pieces of evidence concerning successfully reducing depression with desensitization method have been reported (17-21). Immunizing against stress is one of the lifestyle aspects and some researchers determined the association between stress and physical health factors (22). The results of the researches showed that educating stress management on cancer patients can enhance the effectiveness of chemotherapy (23). The results also showed that educating stress management could create positive feeling in response to breast cancer test along with their late recovery of cellular immunity

The results also showed that educating stress management could create positive feeling in response to breast cancer test among women in the early stages of breast cancer along with their early recovery of cellular immunity (24).

\section{Objectives}

Depression is regarded as the most common mental disorder. Patients with spinal cord injuries are mostly involved with this disorder. Undoubtedly, identification of suitable solutions which can help to reduce depression among patients with spinal cord injuries. As there has been no study focusing on effectiveness of the cognitive therapy, stress management, and desensitization through eye movement reprocessing on depression in these patients, we aimed to compare the effect of these methods on depression severity in patients with spinal cord injuries.

\section{Patients and Methods}

In a quasi-experimental pretest-posttest study, 600 consecutive patients with spinal cord injuries in Hamadan, Iran, were identified among which 60 patients were randomly selected and allocated to one of the following groups: stress management, cognitive group therapy, eye movement desensitization and reprocessing, and no cognitive treatment groups. The first three groups participated in eight structured sessions including 1.5 hours per week for two months while the fourth group received no cognitive treatment. Depression status and severity was determined using Beck depression inventory (BDI) at baseline as well as after completion of the treatment sessions. This scale was developed beck in 1961 based on clinical criteria for depression, consisting of 21 sentences with four choices in each one. Out of 21 sentences, two sentences refer to mood, eleven to cognitive problems, two sentences to cover behaviors, five to bodily signs, and one to interpersonal relationships. The subjects were asked to choose the item compatible mostly with their mood situation. The score of each group of sentences was ranged from zero to three and the sum of scores ranged from three to 63. The studies related to validity and reliability of the test in similar study population were satisfactory with the validity of 0.93 and internal consistency of 0.85 (25). Results were presented as mean \pm standard deviation (SD). Quantitative variables were compared with one-way ANOVA test or nonparametric Kruskal-Wallis H test. The difference in effectiveness of different methods was examined using covariate analysis. Statistical significance was determined as a P value of $\leq 0.05$. All statistical analysis were performed using SPSS software (version 19.0, SPSS Inc., Chicago, IL, USA).

\section{Results}

The study groups had no difference in terms of gender and age distributions. According to BDI, the mean depression score at baseline had no significant difference among the groups with the mean score of $32.80 \pm 3.72$, $32.20 \pm 3.82,33.93 \pm 4.86$, and $33.13 \pm 1.80$ in respectively stress management training, desensitization eye movement reprocessing, cognitive therapy groups, and in those who received no cognitive treatment. However, following training, the mean depression score in the groups received eye movement desensitization (14.60 \pm $3.15)$ and stress management $(22.66 \pm 3.37)$ were significantly lower than in group with cognitive group therapy $(27.33 \pm 4.15)$ or in group of no cognitive treatment $(32.13 \pm 1.80)(\mathrm{P}<0.001)$. Using covariate analysis, a significant difference was revealed in the depression state across three test groups and control group ( $\mathrm{F}=99.94$, Effect size $=0.85, \mathrm{P}<0.001)$. Between-group covariate analysis (Table 1) also showed superiority of eye movement desensitization method on the other treatment methods $(\mathrm{P}<0.001)$. 
Hemmati Sabet A et al.

Table 1. Covariance Analysis of Depression in Different Treatment Groups

\begin{tabular}{|c|c|c|c|c|c|c|}
\hline Groups & Sum Square & Degree Freedom & Mean Square & Frequency & P Value & Mean Difference \\
\hline $\begin{array}{l}\text { Stress Management vs. Cognitive } \\
\text { Therapy }\end{array}$ & 119.99 & 1 & 119.99 & 19.55 & $<0.001$ & 4.02 \\
\hline $\begin{array}{l}\text { Desensitization vs. Stress Manage- } \\
\text { ment }\end{array}$ & 306.08 & 1 & 306.08 & 49.93 & $<0.001$ & 6.59 \\
\hline $\begin{array}{l}\text { Desensitization vs. Cognitive } \\
\text { Therapy }\end{array}$ & 745.20 & 1 & 745.20 & 121.56 & $<0.001$ & 10.62 \\
\hline
\end{tabular}

\section{Discussion}

This research showed more effectiveness of eye movement desensitization method in reducing depression in comparison to the other treatment methods such as stress management and cognitive group therapy. In this regard, it can be suggested that repeated exposure to the different stimulants in education session is a barrier for patients for proceeding treatment. Desensitization through eye movement reprocessing leads to decrease and remove sensitivities against stimulants that discourage responses and behaviors in dictating depression. The approach of desensitization through eye movement consists of history, preparation, and assessment, which is attention to cognitive factors, replacing better recognition through two scales of validity of recognition, and disturbed mental unit, and the stage of implementing the suitable thought during eye movement brought about more efficiency. The approach of desensitization through eye movement consists of history, preparation of referents, and their assessment, which includes attention to cognitive factors, bringing about better recognition. This is done through two scales of validity of recognition, and disturbed mental unit, and the last stage is implementing the suitable thought during eye movement. It seems that using these technique can result in efficacy of this approach compared to other approaches in reducing depression.

In a similar study, it has been shown that desensitization is more effective than group cognitive therapy in reducing depression symptoms in war veterans with depression (26). On the other hand, the reason of success for stress management is its comprehensiveness, ie, there is much attention to cognitive, social, emotional, and physical aspects. In another group, it was indicated that the group training of stress management was more effective than cognitive group therapy in reducing students' social phobia (27). As beliefs and attitudes are the underlying aspects of cognitive therapy, the patients became familiar with the Beck's list of ineffective attitudes and they were taught to fight with these beliefs. Totally, the effect on patients with spinal cord injuries can be attributed to the modification of self-perception, underlying beliefs, interaction style, and increase of activity level.

Limitation of this research was absence of a follow-up stage due to lack of accessibility to the participants.
Among various methods aimed to reduce depression severity in patients who experienced spinal cord injuries, desensitization through eye movement seems to be superior to other methods including stress management and cognitive therapy.

\subsection{Key Point}

Depression is regarded as the most common mental disorder. Patients with spinal cord injury are mostly affected by this disorder. The method of desensitization treatment through eye movement reprocessing has been recently proposed as an influential method in reducing depression. This treatment includes elements of exposure therapy and behavioral therapy combined with eye movements, hand strikes, and audio stimulation. Desensitization treatment accelerates accessibility and reprocessing traumatic memories in a compatible style and helps to release the brain from previous trauma through natural processing of emotional information. Beside the others approved method, desensitization treatment may be a useful method in treatment of depression in patients with spinal cord injury.

\section{Acknowledgements}

This study was supported by the Hamadan University of Medical Sciences. We thank the University authorities who offered critical administrative support and managerial services in performing the study and also all researchers for their help and support.

\section{Authors' Contributions}

Akbar Hemmati Sabet and Mohammad Ahmadpanah drafted the manuscript and conceived and designed the evaluation. Alaleh Ashouri collected the clinical data. Mohammad Hemmati interpreted the clinical data, and Daryush Amini performed the statistical analysis. All authors read and approved the final manuscript.

\section{References}

1. World Health Organization. [updated 2014]; World health report 2013 Research for universal health coverage. 2001. Available from: http://www.who.int/whr/en/. 
2. Salehzadeh M, Kalantari M, Molavi H, Najafi MR, Ebrahimi A. Effectiveness of Cognitive-Behavioral Group Therapyon Depression in Intractable Epileptic Patients. Adv Cogn Sci. 2010;12(2):59-68.

3. Clark DA, Beck AT. Scientific Foundations of Cognitive Theory and Therapy of Depression.New York: John Wiley and Sons; 1999.

4. Zolfaghari A. The investigation of prevalence of depression among students and effect of group cognitive therapy on reduction of it. Iran: Iran Shahed University; 1998.

5. Angest J. Clinical course of effective disorders in depressive illness :prediction of clinical course and outcome.Berlin: Springer; 1988.

6. Saduk BJ, Kaplan V. Summarizing the clinical psychiatric mental health. Behav Sci ;28:419-21.

7. Oei TP, Bullbeck K, Campbell JM. Cognitive change process during group cognitive behaviour therapy for depression. $J$ Affect Disord. 2006;92(2-3):231-41.

8. Embling S. The effectiveness of cognitive behavioural therapy in depression. Nurs Stand. 2002;17(14-15):33-41.

9. Kwon SM, Oei TP. Cognitive change processes in a group cognitive behavior therapy of depression. J Behav Ther Exp Psychiatry. 2003;34(1):73-85.

10. Fava GA, Ruini C, Rafanelli C, Finos L, Conti S, Grandi S. Six-year outcome of cognitive behavior therapy for prevention of recurrent depression. Am J Psychiatry. 2004;161(10):1872-6.

11. Oei TP, Shuttlewood GJ. Comparison of specific and nonspecific factors in a group cognitive therapy for depression.J Behav Ther Exp Psychiatry. 1997;28(3):221-31.

12. Stangier U, Heidenreich T, Peitz M, Lauterbach W, Clark DM. Cognitive therapy for social phobia: individual versus group treatment. Behav Res Ther. 2003;41(9):991-1007.

13. Dobson KS. A meta-analysis of the efficacy of cognitive therapy for depression. J Consult Clin Psychol. 1989;57(3):414-9.

14. Mynors-Wallis L. Problem-solving treatment: evidence for effectiveness and feasibility in primary care. Int J Psychiatry Med. 1996;26(3):249-62.

15. Schulberg HC, Block MR, Madonia MJ, Scott CP, Rodriguez E, Imber SD, et al. Treating major depression in primary care practice. Eight-month clinical outcomes. Arch Gen Psychiatry. 1996;53(10):913-9.
16. Shapiro F, Ed EMDR. Manuals.Dhaka Bangladesh; 1988.

17. Rachman S, Maser J. Panic psychological perspectives.The USA: Law rence Erlbaum Hill sdale; 2007.

18. Happer. M. General Anxiety Disorder. J clin Psychiatry. 2011;67:5873.

19. Becker CB, Zayfert C, Anderson E. A survey of psychologists' attitudes towards and utilization of exposure therapy for PTSD. Behav Res Ther. 2004;42(3):277-92.

20. Rothbaum BO. A controlled study of eye movement desensitization and reprocessing in the treatment of posttraumatic stress disordered sexual assault victims. Bull Menninger Clin. 1997;61(3):317-34

21. Vatankhah H. [Evaluation and comparison of treatment methods Desensitization and Reprocessing through eye movements, medication and cognitive therapy on reducing anxiety of male and female clients referred to Tehran counseling and psychotherapy centers]. Iran: Iran Islamic Azad University Tehran Markaz Unit; 2008.

22. Meichenbuum D. Stress Inoculation Training.Pergamon Press: Network; 1986.

23. Jacobsen PB, Meade CD, Stein KD, Chirikos TN, Small BJ, Ruckdeschel JC. Efficacy and costs of two forms of stress management training for cancer patients undergoing chemotherapy. J Clin Oncol. 2002;20(12):2851-62.

24. McGregor BA, Antoni MH, Boyers A, Alferi SM, Blomberg BB, Carver CS. Cognitive-behavioral stress management increases benefit finding and immune function among women with early-stage breast cancer.J Psychosom Res. 2004;56(1):1-8.

25. Taraghijah S. [Comparing the effect of group counseling with cognitive-behavioral approach and spiritual approach on Tehran girl's student depression]. Iran: Iran Tehran Tarbiat-e-Moallem University; 2007..

26. Ahmadi M, Karami R, Vatankhah $\mathrm{H}$, et al. . The comparison of Eye Movement Desensitization Reprocessing Intervention and group cognitive therapy Efficacy on reducing depression symptoms in depressed war veterans. Iran J Mil psychology. 2012;2(7):19.

27. Hemmati SA, KhalatBari J, Amini D. Camparing the efficacy of group training of stress management and cognitive group therapy on student social phobia. Iran J Clin Pcychology. 2012;2(6):169-89. 